\title{
EGF induces epithelial-mesenchymal transition and cancer stem- like cell properties in human oral cancer cells via promoting Warburg effect
}

\author{
Qilin Xu ${ }^{1}$, Qunzhou Zhang ${ }^{1}$, Yasutaka Ishida ${ }^{1,2}$, Souren Hajjar ${ }^{1}$, Xudong Tang ${ }^{1,3}$, \\ Haoran Shi ${ }^{1}$, Chi V. Dang ${ }^{4}$, Anh D. Le ${ }^{1,5}$ \\ ${ }^{1}$ Department of Oral and Maxillofacial Surgery and Pharmacology, University of Pennsylvania School of Dental Medicine, \\ Philadelphia, Pennsylvania, USA \\ ${ }^{2}$ Department of Molecular Oral Medicine and Maxillofacial Surgery, Graduate School of Biomedical Sciences, Hiroshima \\ University, Japan \\ ${ }^{3}$ Institute of Biochemistry and Molecular Biology, Guangdong Medical University, Zhanjiang, Guangdong, China \\ ${ }^{4}$ Abramson Cancer Center, Perelman School of Medicine at The University of Pennsylvania, Philadelphia, Pennsylvania, USA \\ ${ }^{5}$ Department of Oral \& Maxillofacial Surgery, Penn Medicine Hospital of The University of Pennsylvania, Philadelphia, \\ Pennsylvania, USA \\ Correspondence to: Anh D. Le, email: Anh.Le@uphs.upenn.edu
}

Keywords: EGF, EMT, cancer stem cells, Warburg effect, oral cancer

Received: June 30,2016 Accepted: November 21,2016 Published: December 01, 2016

\section{ABSTRACT}

"Warburg effect", the enhanced glycolysis or aerobic glycolysis, confers cancer cells the ability to survive and proliferate even under stressed conditions. In this study, we explored the role of epidermal growth factor (EGF) in orchestrating Warburg effect, the epithelial-mesenchymal transition (EMT) process, and the acquisition of cancer stem-like cell properties in human oral squamous cell carcinoma (OSCC) cells. Our results showed that EGF induces EMT process in OSCC cells, which correlates with the acquisition of cancer stem-like properties, including the enrichment of $\mathrm{CD}^{2}{ }^{+} / \mathrm{CD}$ 24- $^{-}$population of cancer cells and an increased expression of CSC-related genes, aldehyde dehydrogenase-1 (ALDH1) and Bmi-1. We also showed that EGF concomitantly enhanced L-lactate production, while blocking glycolysis by 2-deoxyD-glucose (2-DG) robustly reversed EGF-induced EMT process and CSC-like properties in OSCC cells. Mechanistically, we demonstrated that EGF promoted EMT process and CSC generation through EGFR/PI3K/HIF-1 $\alpha$ axis-orchestrated glycolysis. Using an orthotopic tumor model of human OSCC (UM-SCC1) injected in the tongue of BALB/C nude mice, we showed that treatment with 2-DG in vivo significantly inhibited the metastasis of tumor cells to the regional cervical lymph nodes and reduced the expression of ALDH1 and vimentin in both in situ tumors and tumor cell-invaded regional lymph nodes. Taken together, these findings have unveiled a new mechanism that EGF drives OSCC metastasis through induction of EMT process and CSC generation, which is driven by an enhanced glycolytic metabolic program in OSCC cells.

\section{INTRODUCTION}

Head and neck squamous cell carcinoma (HNSCC) is one of the 10 most common cancers in the world with more than half a million new cases per year globally, while oral squamous cell carcinoma (OSCC) represents the majority of HNSCC with $\sim 25,000$ new cases diagnosed each year in the U.S. alone [1]. Over half of the patients with head and neck cancer present with locally advanced disease manifested as regional and distant metastases, which contributes to a considerable proportion of the treatment failures and consequently, a $\sim 50 \%$ reduction of survival rates [2-4). Despite advances in treatment, the 5-year survival still remains disappointing and most of the patients with recurrent or metastatic disease die within a year $[4,5]$. An increasing understanding of the 
complex metastases/recurrence mechanisms of head and neck cancer is imperative to the development of effective and mechanism-based therapeutic modalities for this malignancy.

Epidermal growth factor receptor (EGFR) is a member of the ERBB family of cell-surface tyrosine kinases [6]. It has been reported that more than $90 \%$ of head and neck squamous cell carcinomas (HNSCC) overexpress epidermal growth factor receptors (EGFRs), which play an important role in tumor progression and treatment resistance and emerge as important targets for the treatment of HNSCC $[4,7]$. Two classes of agents have been explored as specific inhibitors of EGFRs, monoclonal antibodies directed against the extracellular domain of EGFRs and synthetic small molecule tyrosine kinase inhibitors (TKIs) that act directly on the cytoplasmic domain of EGFR TK activity [8]. However, the enthusiasm with EGFR-targeted therapies has been confronted with challenges associated with de novo and acquired resistance $[6,9,10]$. Therefore, EGFR-targeted therapies are usually combined with either chemo- or radiation therapies due to the unsatisfactory response rates $(\sim 13 \%)$ as a monotherapy $[11,12]$.

Cancer cells in the primary tumor can lose cellcell adhesion and break through the basement membrane with increased invasive properties and enter the bloodstream through extravasation, a process driven by epithelial-mesenchymal transition (EMT) process. The circulating tumor cells then exit the bloodstream to form micrometastases, where they undergo mesenchymalepithelial transition (MET) for clonal outgrowth. Thus, EMT and MET constitute the initiation and completion of the invasion-metastasis cascades. However, the cellular and molecular signals within the tumor microenvironment that orchestrate this complex process are still largely unknown [13]. Cancer stem cells (CSCs) or tumor initiating cells (TICs) represent a small subpopulation of tumor cells that may play a critical role in cancer recurrence, relapse, and metastasis due to their highly tumorigenic, self-renewal, and differentiation capabilities [14]. CSC-like cells have also been identified in head and neck cancer based on the expression of different cellular markers [15-20]. Several lines of evidence have shown that CSCs represent a plastic state of tumor cells undergoing EMT process triggered by various cell-intrinsic or microenvironmental signals $[21,22]$, however, the exact origin of these unique stemlike cancer cells remains largely unknown. The inherent plastic property of CSCs further supports the notion that even specifically targeting CSCs alone may not be effective to eradicate cancer; thus, multiple combination modalities are necessary to target both CSCs and their unique microenvironment [14]. Accumulating evidence has shown that cancer cells have the ability to rewire their glucose metabolism and energy supply toward glycolysis even in the presence of oxygen, a phenomenon termed Warburg effect or aerobic glycolysis [23, 24].
The aberrant metabolic reprogramming, particularly an increased glycolytic metabolism, can facilitate cancer cells to undergo EMT process and acquire CSC-like properties, thus promoting tumor initiation and progression [25-27]. Therefore, reversing the aberrant metabolic reprogramming of cancer cells is a potential therapeutic approach for cancer therapies [28, 29].

Several lines of evidence have demonstrated that EGF can induce EMT in various types of cancer cells, including breast cancer [30], prostate cancer [31, 32], cervical cancer [33], and head and neck cancer [22, 34]. Meanwhile, EGF stimulation endows head and neck cancer cells with stem-like cell properties [22]. However, the molecular mechanisms underlying EGFinduced CSC phenotypes remain elusive. In the current study, we investigated the potential role of glucose metabolic reprogramming in EGF-induced EMT and cancer stem-like properties in OSCC cells. We showed that EGF enhanced L-lactate production while blocking glycolysis by 2-DG robustly reversed EGF-induced EMT process and CSC-like phenotypes in OSCC cells. Importantly, we demonstrated that in vivo treatment with 2-DG significantly inhibited metastasis of tumor cells to regional lymph nodes and robustly reduced the expression of EMT- and CSC-related genes in both the in situ tumors and invaded regional lymph nodes. These findings suggest that EGF promotes OSCC metastasis through induction of EMT and CSC generation, which is driven by an enhanced glycolytic metabolic program in OSCC cells.

\section{RESULTS}

\section{EGF induces EMT process in OSCC cells}

Initially, we determined the effect of EGF on a panel of established OSCC cell lines and found that two representative cell lines, SCC-1 and SCC-116, underwent typical mesenchymal-like morphological changes characteristic of the EMT phenotype in response to EGF stimulation (Supplementary Figure 1, Figure 1A). EGF-induced EMT process in SCC-1 cells was further confirmed by a dose-dependent decrease in the expression of E-cadherin, a specific cell surface marker for epithelial cells, along with a simultaneous increase in the expression of vimentin, a mesenchymal-related marker (Figure 1B and 1C). The EGF-induced EMT process was also characterized by an increased expression of EMTregulatory transcription factors, such as Zeb1 and slug, and a decrease in ZO-1, another epithelial cell marker (Figure 1D). Knocking down the expression of Slug and Zeb1 partially abrogated the downregulation of E-cadherin expression and completely abolished the upregulation of vimentin expression induced by EGF in SCC-1 cells (Supplementary Figure 2), suggesting that Slug and Zeb1 contribute to EGF-induced EMT process in SCC-1 cells. 
Meanwhile, we showed that EGF significantly increased the invasive capacity of SCC-1 cells (Figure 1E), but had little effects on their proliferation rate (Figure 1F), thus ruling out the possibility that the increased number of invasive cells was due to EGF-mediated effect on SCC1 cell proliferation. These findings suggest that EGF induces EMT process and promotes invasion of SCC-1 cells in vitro.

\section{EGF endows OSCC cells with stem-like cell properties}

We next determined the effect of EGF on CSC-like cell properties in SCC-1 cells. Flow cytometric analysis showed that a small population of SCC-1 cells $(\sim 7-8 \%)$ was positive for CD44 (Figure 2A), a commonly used cell surface marker for head and neck cancer stem-like cells [19, 22], while EGF stimulation upregulated CD44 expression and significantly enriched the fraction of CD $44^{+} / \mathrm{CD} 24^{\text {low } /-}$ cells (Figure $2 \mathrm{~A}$ ). In addition, EGF not only increased vimentin expression but also significantly enhanced the expression of aldehyde dehydrogenase 1 (ALDH1) and Bmi-1 (Figure 2B and 2C), another two stem cell-related genes popularly expressed in CSC-like cells in HNSCC $[19,22]$. We then determine whether EGF-induced CSC-like cells endowed with EMT phenotypes. To this purpose, $\mathrm{CD} 44^{+} / \mathrm{CD} 24^{\text {low } /-} \mathrm{CSC}$-like cells were purified from EGF-treated SCC-1 cells and exhibited a decreased expression of E-cadherin and a concomitant increased expression of vimentin as compared to their counterparts, CD44-/CD24 ${ }^{\text {low/- }}$ cells (Figure 2D). Functionally, we showed that $\mathrm{CD} 44^{+} / \mathrm{CD} 24^{\text {low } /-}$ CSC-like

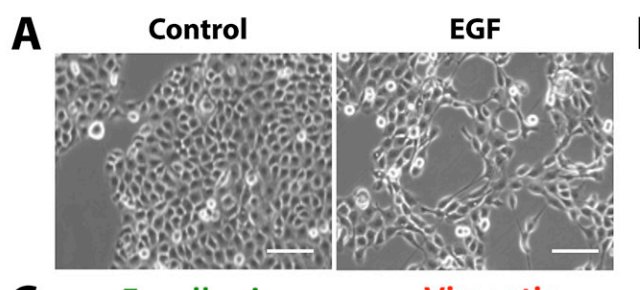

B
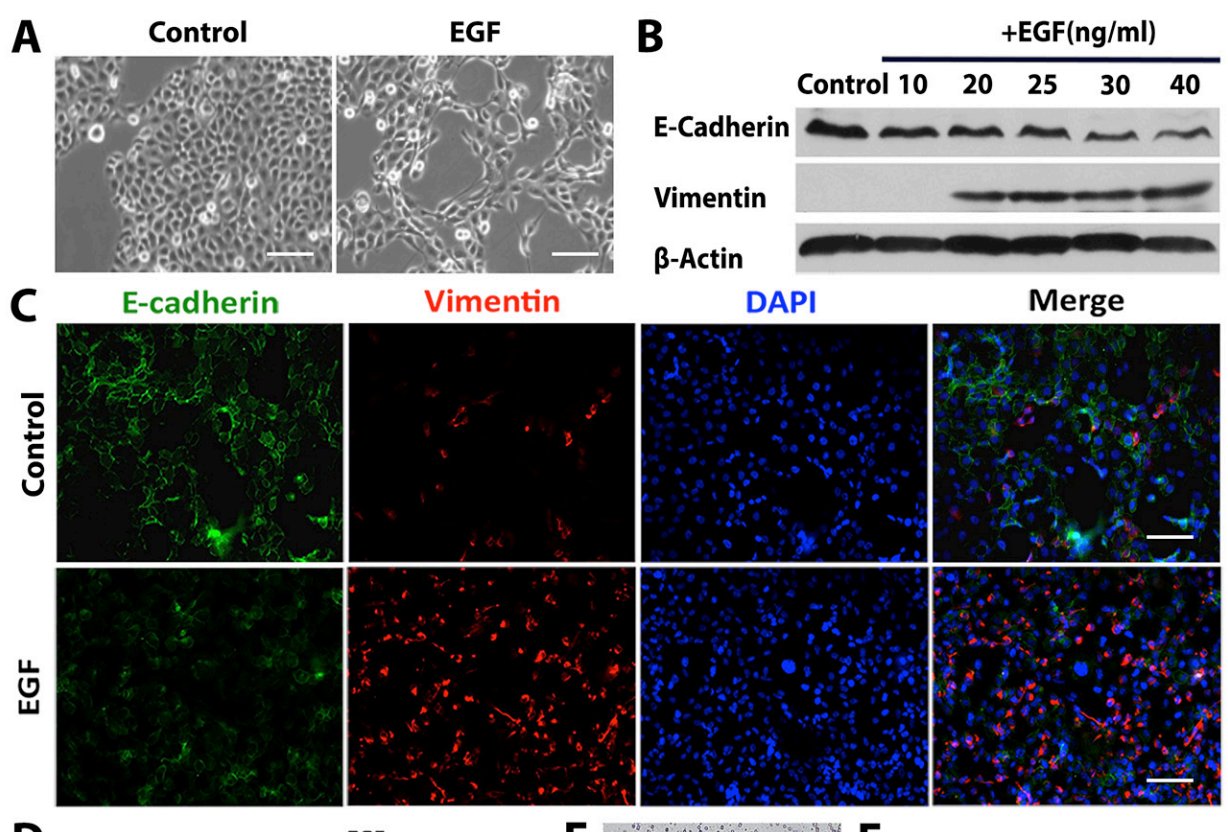
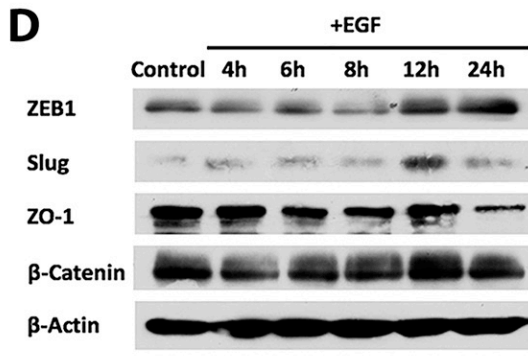

E

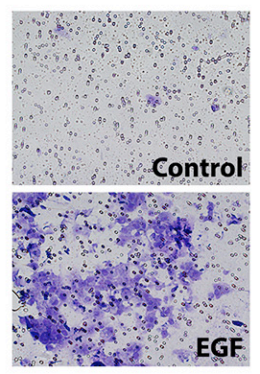

$\mathbf{F}$ SCC-1 proliferation (MTT)

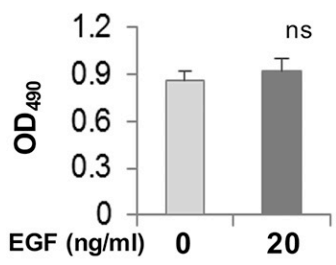

Figure 1: EGF induces EMT process in OSCC cells. A. Morphologic changes in SCC-1 cells in response to EGF stimulation for $48 \mathrm{~h}$. Scale bars, $100 \mu \mathrm{m}$. B. The expression of vimentin and E-cadherin proteins in SCC-1 cells treated with different concentrations of EGF for $48 \mathrm{~h}$ was determined by Western blot, while the expression of $\beta$-actin was used as internal controls. C. Immunofluorescence staining of vimentin (Red) and E-cadherin (Green) in SCC-1 cells stimulated with $20 \mathrm{ng} / \mathrm{mL}$ EGF for $48 \mathrm{~h}$ was observed under a fluorescence microscope. The nuclei were counter stained with 4', 6-diamidino-2-phenylindole (DAPI). Scale bars, 100 $\mu \mathrm{m}$. D. The expression of ZEB1, Slug, ZO-1 and $\beta$-Catenin proteins in SCC-1 cells treated with $20 \mathrm{ng} / \mathrm{mL}$ EGF for different time periods was determined by Western blot, while the expression of $\beta$-actin was used as internal controls. E. Stimulation with $20 \mathrm{ng} / \mathrm{mL}$ EGF for $48 \mathrm{~h}$ enhanced the invasiveness of SCC1 cells as evaluated by Matrigel invasion assay. F. EGF $(20 \mathrm{ng} / \mathrm{mL})$ stimulation for $48 \mathrm{~h}$ showed no obvious effects on cell proliferation of SCC-1 cells as determined by MTT assay. ns, no significant statistical difference. 
cells intrinsically exhibited increased invasion ability as compared with their $\mathrm{CD} 44^{-} / \mathrm{CD} 24^{\text {low/- }}$ counterparts in the absence of EGF stimulation (Figure 2E). Collectively, these findings suggest that EGF-induced EMT process may play a role in the generation of CSC-like cells with increased invasive capability.

\section{EGF-induced EMT and CSC-like cell properties depend on aerobic glycolysis}

We then determined the effect of EGF on glycolysis $[28,35]$ in SCC-1 cells. Our results showed a two-fold increase in the production of lactate in the supernatants of
SCC-1 cells after EGF stimulation for 24h (Figure 3A). As expected, pretreatment of SCC-1 cells with various concentrations of 2-deoxy-glucose (2-DG), a glycolysis inhibitor, reduced both the basal and EGF-stimulated lactate production in a dose-dependent manner (Figure 3B). To determine the correlation of EGF-induced EMT and glycolysis, SCC-1 cells were stimulated with EGF in the presence or absence of 2-DG for 48h. Our results showed that the presence of 2-DG significantly prevented mesenchymal-like cell morphological changes in EGFstimulated SCC-1 cells (Figure 3C). Concurrently, EGF-induced down-regulation of E-cadherin and upregulation of vimentin expressions were reversed by

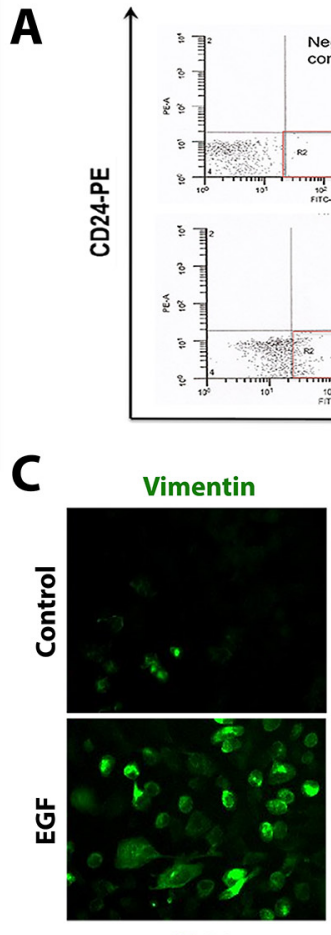

CD44

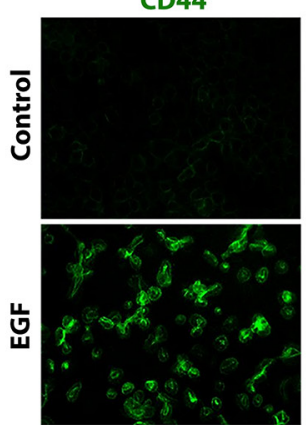

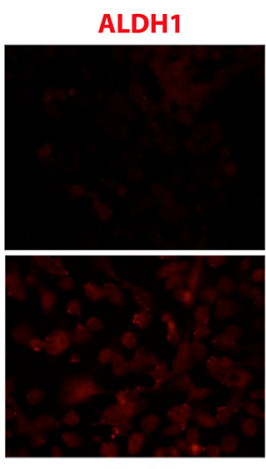

Bmi1

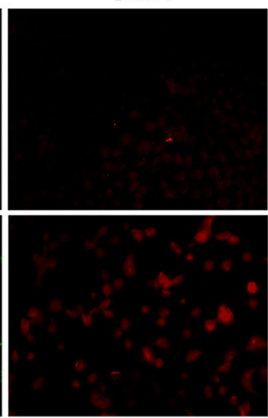

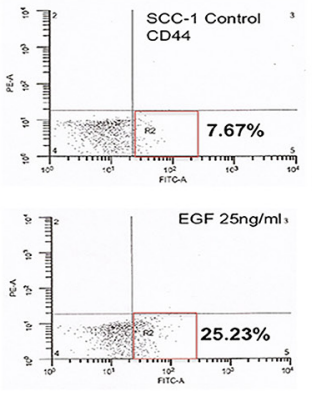

CD44-FITC

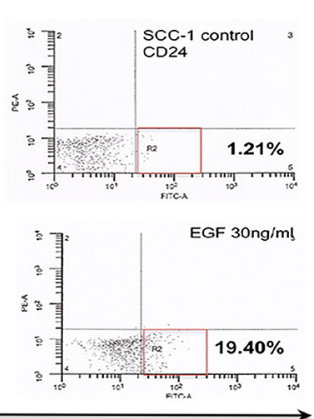

DAPI

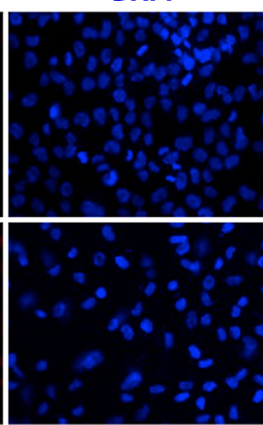

DAPI

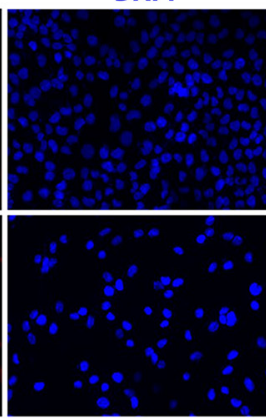

B

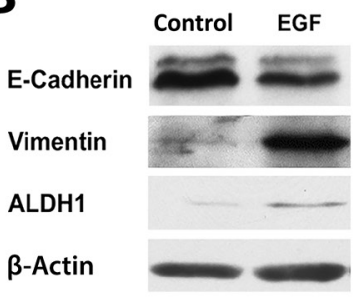

D

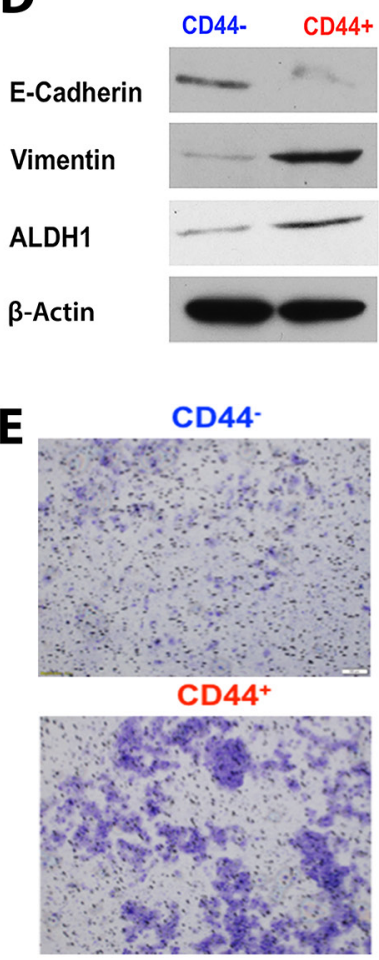

Figure 2: EGF endows OSCC cells with stem-like cell properties. A. SCC-1 cells were stimulated with different concentrations of EGF for 48h and immunostained with FITC-conjugated anti-human CD44 and PE-conjugated anti-human CD24 antibodies and subjected for flow cytometric analysis. B. and C. The expression of vimentin, ALDH1, CD44 and Bmi1 in SCC-1 cells stimulated with 20ng/mL EGF for $48 \mathrm{~h}$ was determined by dual-color immunofluorescence staining $(\mathrm{B})$ and Western blot analysis $(\mathrm{C})$. The nuclei were counter stained with 4', 6-diamidino-2-phenylindole (DAPI). Scale bars, $50 \mu \mathrm{m}$. D. The expression of vimentin, E-cadherin, and ALDH1 in purified CD44 ${ }^{+}$and CD44- cells was determined by Western blot, while the expression of $\beta$-actin was used as internal controls. E. Cell invasiveness of purified $\mathrm{CD}_{4} 4^{+}$and $\mathrm{CD}_{4} 4^{-}$cells in the absence of EGF stimulation was determined by Matrigel invasion assay. 
A

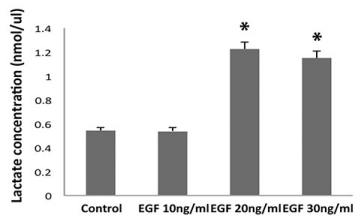

B

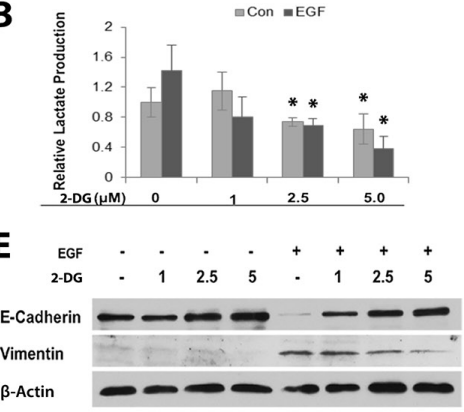

$\mathbf{F}$

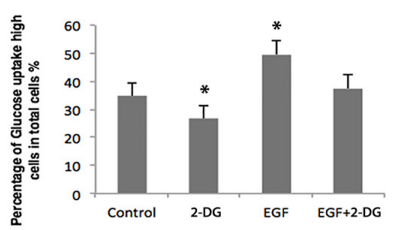

G

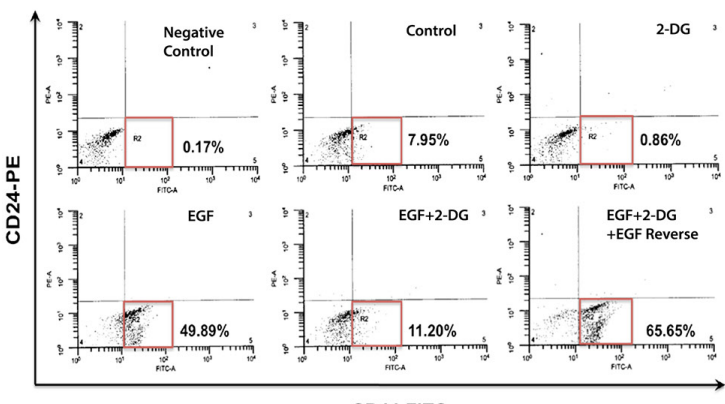

CD44-FITC

H

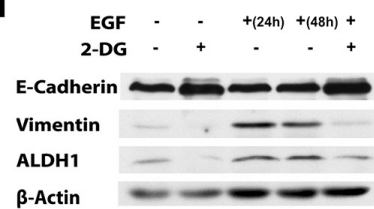

C

D

E-Cadherin

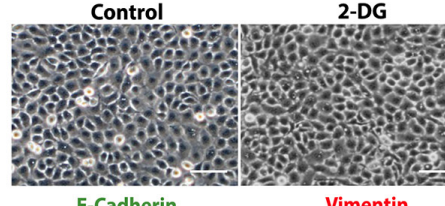

Vimentin
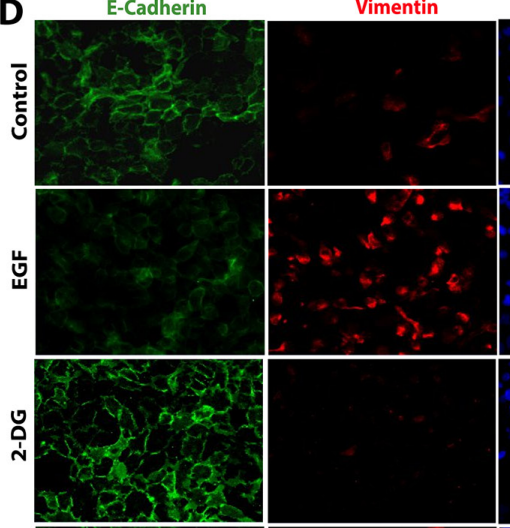

EGF

EGF+2-DG

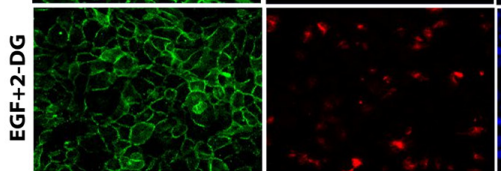

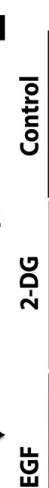

ALDH1
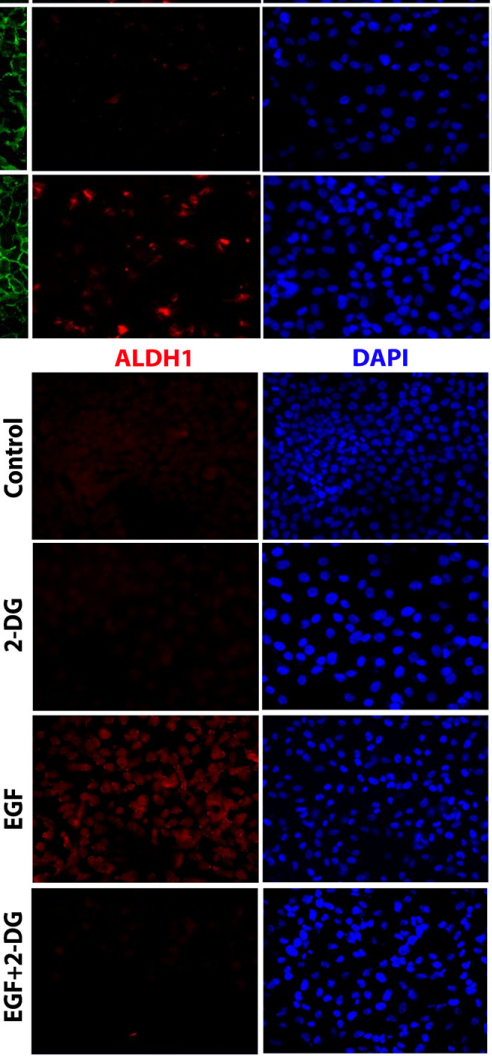

DAPI
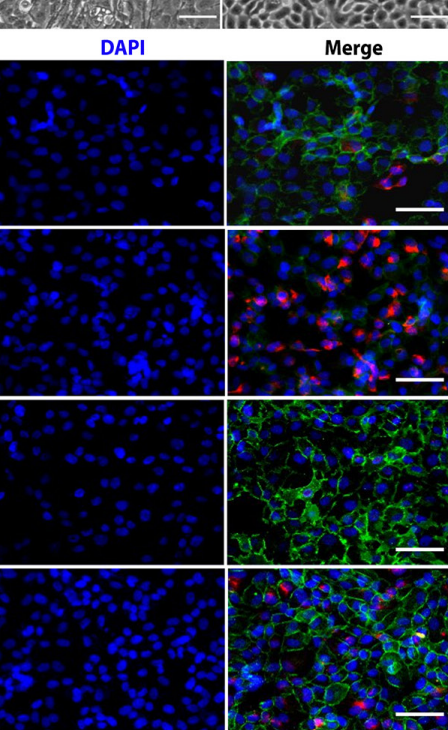

DAPI

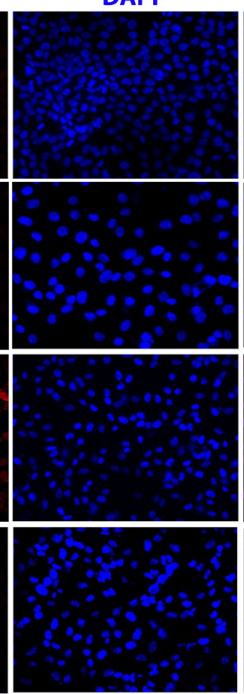

Merge
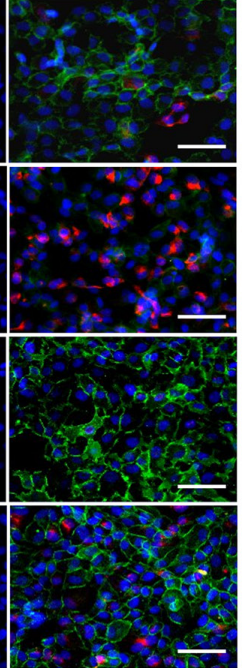

Merge
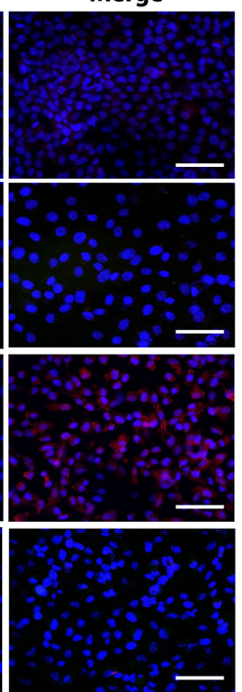

Figure 3: Glycolysis promotes EMT process and generation of $\mathrm{CD}^{+} 4^{+} \mathrm{CD}^{\mathrm{low} /-} \mathrm{CSC}$-like cells in OSCC cells. A. The lactate production in the supernatants of SCC-1 cells after stimulated with different concentrations of EGF for 24h was determined using a Lactate Assay kit. B. SCC-1 cells were stimulated with 20ng/mL EGF in the presence or absence of 5mM 2-DG for 24h and the lactate production in the supernatants was analyzed. ${ }^{*} P<0.05$. C. SCC-1 cells were stimulated with $20 \mathrm{ng} / \mathrm{mL}$ EGF in the presence or absence of $5 \mathrm{mM} 2$-DG for $48 \mathrm{~h}$ and cell morphological changes were observed under a microscope. Scale bars, $100 \mu \mathrm{m}$. D. The combinatorial expression of E-cadherin (Green) and vimentin (Red) in SCC-1 cells stimulated with $20 \mathrm{ng} / \mathrm{mL}$ EGF for $48 \mathrm{~h}$ in the presence or absence of 5mM 2-DG was determined by dual-color immunofluorescence staining and observed under a fluorescence microscope. The nuclei

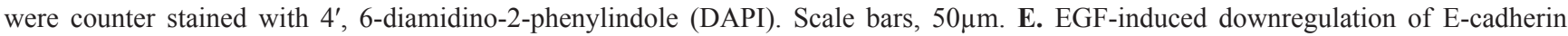
expression and up-regulation of vimentin expression in SCC-1 cells were reversed by 2-DG treatment as determined by Western blot, while the expression of $\beta$-actin was used as internal controls. F. The uptake of glucose in SCC-1 cells stimulated with $20 \mathrm{ng} / \mathrm{mL}$ EGF in the presence or absence of 5mM 2-DG was determined by using a Glucose Uptake Cell-based Assay Kit. ${ }^{*} P<0.05$. G. 2-DG treatment reduced the proportion of $\mathrm{CD}_{4} 4^{+} / \mathrm{CD} 24^{\text {low }}$ cells in SCC-1 cells with or without EGF stimulation as determined by flow cytometry. H. The downregulation of E-cadherin expression and the upregulation of vimentin and ALDH1 expressions induced by stimulation of SCC-1 cells with $20 \mathrm{ng} / \mathrm{mL}$ EGF for $24 \mathrm{~h}$ were reversed by 2-DG treatment for another $24 \mathrm{~h}$ as determined by Western blot, while the expression of $\beta$-actin was used as internal controls. I. The increased expression of ALDH1 in SCC-1 cells induced by stimulation with $20 \mathrm{ng} / \mathrm{mL}$ EGF for $48 \mathrm{~h}$ was abolished by the presence of $5 \mathrm{mM} 2-\mathrm{DG}$ as determined by immunofluorescence studies. The nuclei were counter stained with 4', 6-diamidino-2-phenylindole (DAPI). Scale bars, $50 \mu \mathrm{m}$. 
2-DG treatment as determined by immunofluorescence studies and Western blot analysis, respectively (Figure 3D and 3E). Meanwhile, EGF-stimulated SCC-1 cells showed a significant increase in glucose uptake as compared to untreated cells, which was also robustly attenuated by 2-DG (Figure 3F). Using another OSCC cell line, SCC-116, we also showed that EGF induced EMT phenotypes characterized by spindle-like cell morphological changes, a downregulation of E-Cadherin expression and a concomitant upregulation of vimentin, Zeb, and Slug expressions, which correlated with an increased expression of stem cell-related genes, ALDH1 and Bmi-1 (Supplementary Figure 3A and 3B). Similarly, EGF significantly increased the lactate production (Supplementary Figure 3D), whereas treatment with 2-DG reversed EGF-induced EMT phenotypes in SCC116 cells (Supplementary Figure 3C and 3E). These findings suggest that EGF-induced EMT process depends on glycolysis in OSCC cells.

Next, we tested whether glycolysis is also essential to the acquisition of CSC-like cell properties in OSCC cells. Flow cytometric analysis showed that 2-DG treatment markedly reduced the percentage of $\mathrm{CD}_{4} 4^{+} /$ CD24 $4^{\text {low/- }}$ subpopulation, from $7.9 \%$ to $0.86 \%$ in the parental SCC-1 cells and from $49.9 \%$ to $11.2 \%$ in EGFpretreated SCC-1 cells, respectively (Figure 3G). Of note, the downregulation of E-cadherin expression and the upregulation of vimentin and ALDH1 expressions induced by stimulation of SCC-1 cells with $20 \mathrm{ng} / \mathrm{mL}$ EGF for $24 \mathrm{~h}$ were reversed by 2-DG treatment for another $24 \mathrm{~h}$ (Figure $3 \mathrm{H}$ and 3I). Interestingly, following the withdrawal of 2-DG, re-stimulation of SCC-1 cells with EGF in fresh medium restored the percentage of $\mathrm{CD}_{4} 4^{+} /$ CD24 ${ }^{\text {low/- }}$ subpopulation; while during this reversal EMT process, the heterogeneous cancer cells may undergo nonsynchronous morphological changes (mesenchymal and epithelial-like morphologies), thus making them shown as two groups on the dot plots of flow cytometric analysis (Figure 3G; the lower right panel). These results further support the notion that glycolysis may have driven EGFinduced EMT process and CSC-like cell generation in oral cancer cells.

\section{EGF promotes glycolysis/EMT/CSC-like cell formation through EGFR/PI3K signaling pathways}

We then explored whether EGFR-activated signaling pathways are involved in the regulation of EGF-induced glycolysis/EMT/CSC-like cell generation. As expected, EGF stimulation resulted in EGFR phosphorylation at several specific tyrosine residues (including Tyr992, 1045,1068 ) and correspondingly, the activation of its downstream signaling pathways, including pAkt, pS6Kp70, and mTOR, which was completely blocked by erlotinib, a specific EGFR tyrosine kinase inhibitor
(TKI) (Figure 4A). Blocking PI3K activity by LY294002 completely abolished EGF-induced phosphorylation/ activation of Akt, pS6K70, and mTOR (Figure 4A); treatment with AKT inhibitor (AKTi) blocked EGFinduced phosphorylation of both Akt and mTOR, but had little effects on pS6Kp70, while rapamycin, a specific inhibitor of mTOR, completely blocked EGF-induced mTOR activation but without any obvious effects on Akt and pS6Kp70 activation (Figure 4A). These findings suggest that EGF exerts its biological effects through the activation of EGFR/PI3K/Akt/mTOR signaling cascades in SCC-1 cells.

Next, we determined the role of EGFR signaling pathways in the regulation of EGF-induced EMT process and CSC-like phenotypes in SCC-1 cells. We found that blocking EGFR, PI3K or mTOR activities with erlotinib, LY294002 or rapamycin significantly abrogated EGFinduced mesenchymal-like morphological changes and the downregulation of E-cadherin expression in SCC1 cells, while the AKT inhibitor showed no obvious effects (Figure 4B and 4C). Additionally, blocking EGFR, PI3K or mTOR activities, but not AKT activation, also markedly attenuated EGF-induced up-regulation of ALDH1 expression in SCC-1 cells as determined by immunofluorescence staining and flow cytometric analysis (Figure 4C and 4D). Functionally, we showed that blockade of EGFR/PI3K/AKT/mTOR signaling pathways significantly abrogated EGF-induced invasive abilities of SCC-1 cells (Figure 4E). Similar to 2-DG treatment, blocking either EGFR or PI3K activity significantly attenuated EGF-stimulated lactate production in SCC-1 cells (Figure 4F). Taken together, these findings suggest that EGF induces glycolysis/EMT/CSC-like cell properties in $\mathrm{SCC}-1$ cells via EGFR/PI3K/mTOR-dependent but AKT-independent mechanisms. Further studies are warranted to delineate the detailed mechanisms that integrate EGF-induced glycolysis, EMT process and CSClike cell generation.

\section{EGF induces EMT process via EGFR/PI3K signaling-mediated PDK1 expression in SCC-1 cells}

A recent study has demonstrated the cross-talk between EGFR activation and pyruvate dehydrogenase kinase 1 (PDK1), one of the key metabolic regulators of glycolysis [28]. We then determined the role of EGFR signaling pathways in the regulation of PDK1 expression in OSCC cells. Our results showed that EGF potently induced PDK1 expression in both SCC-1 (Figure 5A and 5B) and SCC-116 (Supplementary Figure 3B). The increase in PDK1 expression in SCC-1 cells started as early as $4 \mathrm{~h}$ post EGF stimulation, which happened earlier than EGF-induced upregulation of Slug expression, a key EMT-regulatory transcription factor (Figure 5B). Interestingly, blocking EGFR and PI3K activities, but 


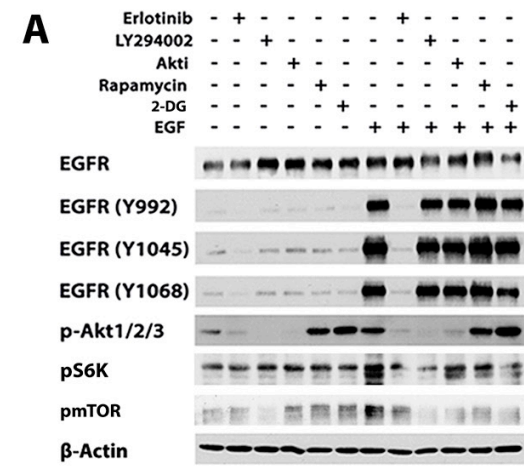

C
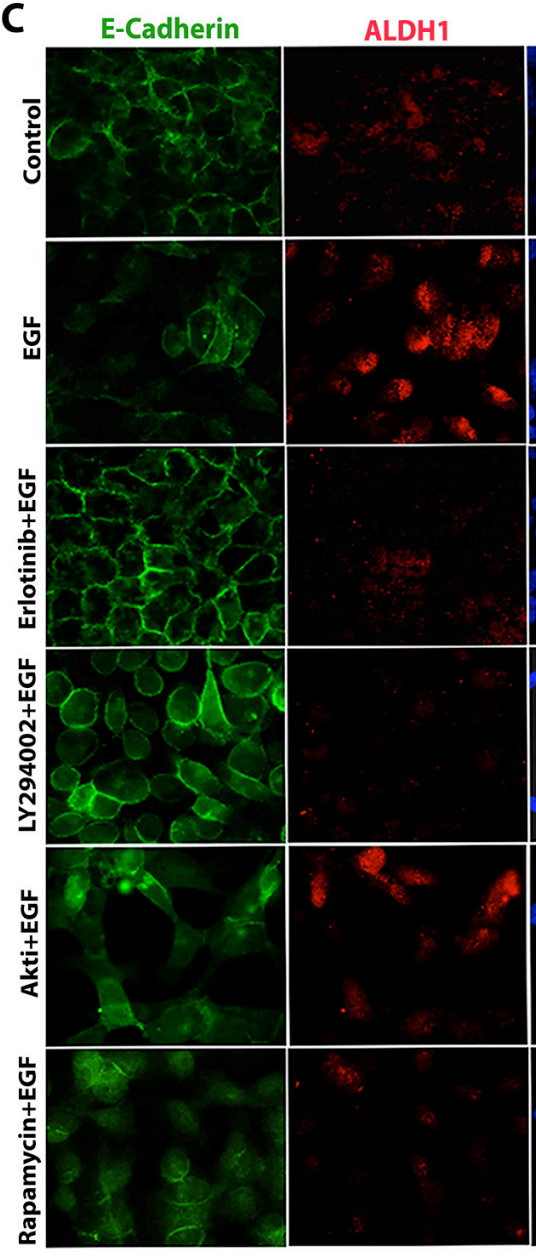

B

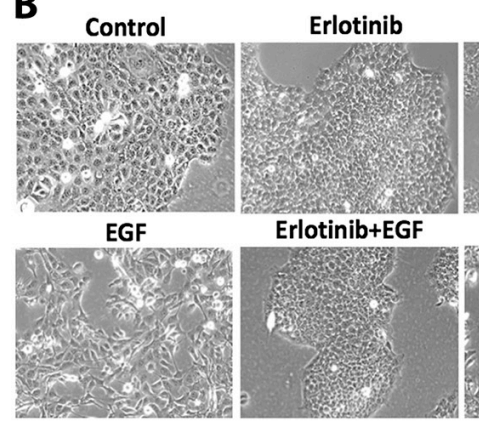

DAPI

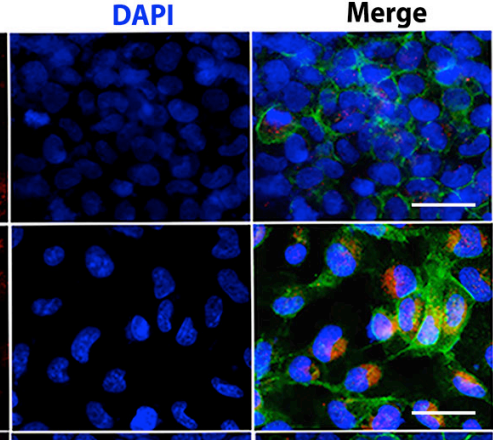

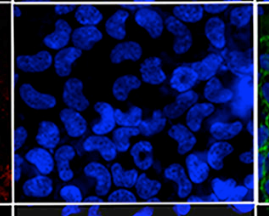
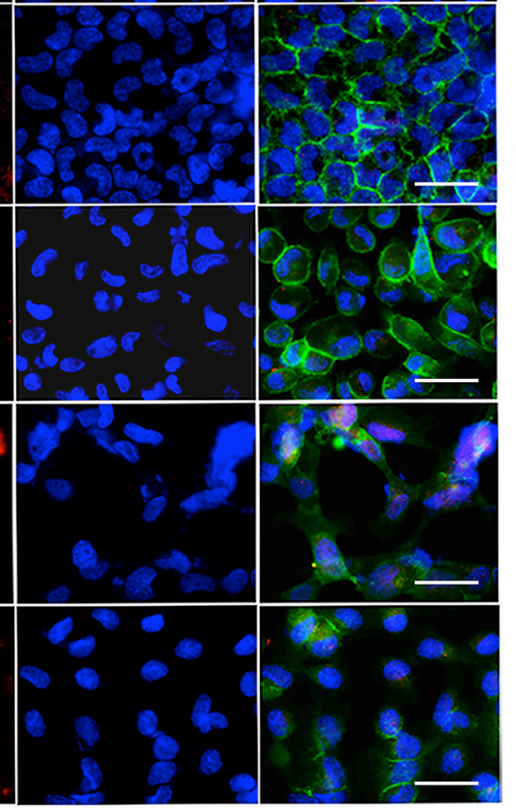

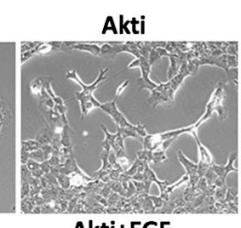

Akti+EGF
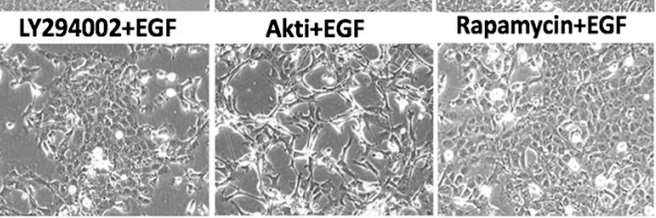

D

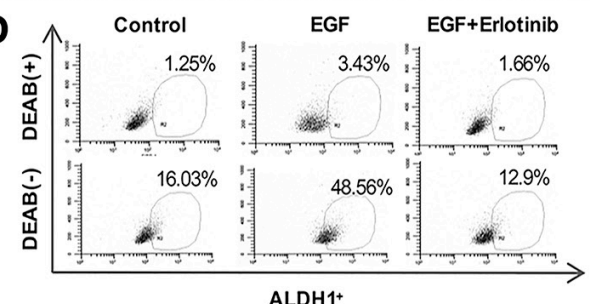

ALDH1+

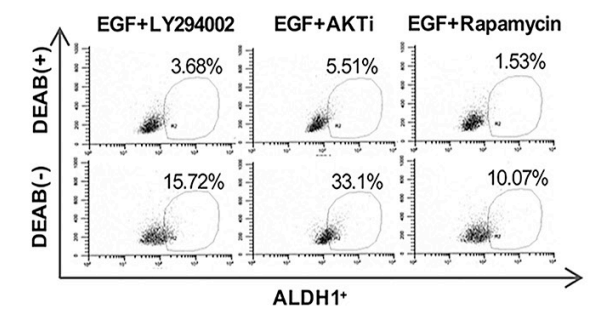

$\mathbf{E}$
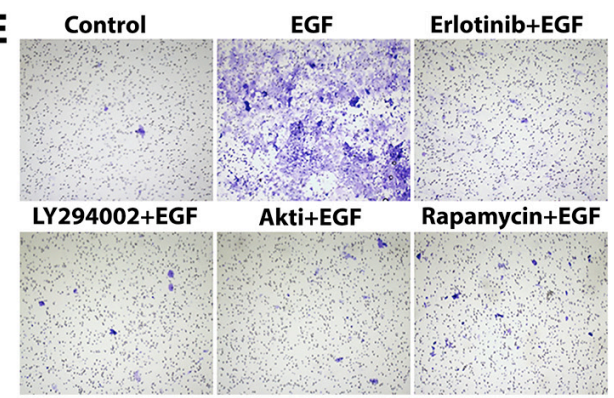

$\mathbf{F}$

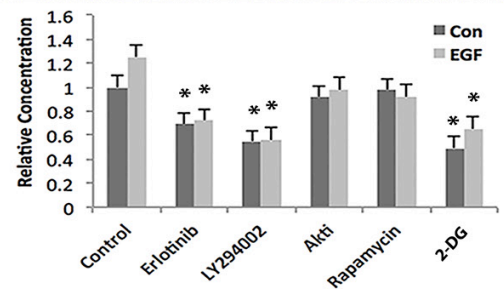

Figure 4: EGF promotes glycolysis/EMT/CSC formation through EGFR/PI3K/mTOR signaling pathway in OSCC cells. A. SCC-1 cells were pretreated with specific inhibitors for EGFR (Erlotinib), PI3K (LY294002), Akt (AKTi), mTOR (rapamycin) or 2-DG for $1 \mathrm{~h}$ followed by stimulation with or without EGF for $4 \mathrm{~h}$ and the expression of EGFR, phosphorylated EGFRs, p-Akt, pS6K, and $\mathrm{p}$-mTOR was determined by Western blot. The expression of $\beta$-actin was used as internal controls. B. Following similar treatment as describe in (A), the morphological changes in SCC-1 cells were observed under a microscope. Scale bars, $100 \mu \mathrm{m}$. C. Following similar treatment as describe in (A), the combinatorial expressions of ALDH1 (Red) and E-cadherin (Green) in SCC-1 cells was determined by immunofluorescence studies and observed under a fluorescence microscope; the nuclei were counter stained with 4', 6-diamidino-2phenylindole (DAPI). Scale bars, $20 \mu \mathrm{m}$. D. Following similar treatment as describe in (A), SCC-1 cells were collected, stained with an ALDEFLUOR ${ }^{\mathrm{TM}} \mathrm{Kit}$, and analyzed by flow cytometry. E. The effects of various inhibitors of EGFR-mediated signaling pathways on EGFstimulated invasiveness of SCC-1 cells were evaluated by using Matrigel invasion assay. F. Following similar treatment as describe in (A), the lactate production in the supernatants of SCC-1 cells was determined using a Lactate Assay kit. ${ }^{*} P<0.05$. 
not the AKT and mTORC1 activities, almost completely abrogated EGF-induced PDK1 upregulation, which was coupled with the reversal of EGF-induced EMT phenotypes in SCC-1 cells, specifically, the downregulated E-cadherin expression and the upregulated expression of vimentin (Figure 5C). Of note, such effects conferred by blockade of EGFR and PI3K activities on EGF-induced PDK1 expression and reversal of EMT phenotypes, were comparable to those mediated by 2-DG treatment (Figure 5C). Meanwhile, our results showed that EGF significantly upregulated HIF- $1 \alpha$ protein expression, a transcription factor that cooperates with c-Myc to drive the PDK1 expression and facilitate glycolysis [36-38], which is correlated with EGF-induced upregulation of PDK1 in SCC-1 cells (Figure 5C). However, EGF has no direct effect on c-Myc expression (Figure 5C). Taken together, these findings suggest that EGFR/PI3K/HIF-1 $\alpha$ signaling-orchestrated glycolysis may play an important role in EGF-induced EMT process in OSCC cells.

\section{Blocking glycolysis suppressed EGF-facilitated metastasis of OSCC cells to regional cervical lymph nodes}

We next determined the critical role of glycolysis in EGF-facilitated regional cervical lymph node (LN) metastasis in an orthotopic tumor model of human OSCC in the tongue of nude mice. To this purpose, SCC-1 cells were stably transduced with a GFP-expressing lentiviral vector (Supplementary Figure 4A). These GFP-tagged SCC-1 cells underwent EMT process in response to EGF stimulation, which could also be reversed by 2-DG treatment in vitro (Supplementary Figure 4A). Following submucosal injection into the tongue of nude mice, GFP-tagged SCC-1 cells steadily formed tumors (Figure 6A; Supplementary Figure 4B), and about 20\% of mice developed regional cervical LN metastasis as evidenced by the local presence of GFP-tagged SCC1 cells (Supplementary Figure 4C, Table 1). Upon transplantation in a mixture of hydrogel with EGF (20ng/ $\mathrm{mL}$ ), SCC-1 formed tumors in situ with similar sizes to those without EGF (Supplementary Figure 4B), suggesting that EGF did not promote the growth of the in situ tumors. However, the presence of EGF enhanced the expression of ALDH1, vimentin, and PDK1in the in situ tumors in the tongue (Figure 6A and 6D) and increased the incidence of cervical LN metastasis ( $70 \%$ versus $20 \%$ of the control group; $\mathrm{p}=0.038$ ) (Fig. S4C, Table 1 ). Additionally, our results showed that the metastatic tumor cells in the cervical LNs positively expressed vimentin, ALDH1 (Figure 6B and 6C), and PDK1 (Figure 6D), suggesting they were endowed with EMT and CSC-like phenotypes. Importantly, our data indicated that 2-DG treatment had no obvious inhibitory effects on the in situ tumor growth (Supplementary Figure 4B), but dramatically reduced the degree and incidence of EGF-facilitated cervical LN metastases of SCC- 1 cells ( $30 \%$ versus $70 \%$ ) even though there was no significant statistic difference (Figure 6C, Table $1 ; \mathrm{p}=0.101)$. Collectively, these in vivo findings support that glycolysis plays a pivotal role in EGFfacilitated metastasis of OSCC cells.

\section{DISCUSSION}

The epithelial-mesenchymal transition (EMT) process constitutes a crucial step in the invasion and metastatic spread of a variety of epithelial cancers [14]. This phenotypic transition process is dynamic, reversible

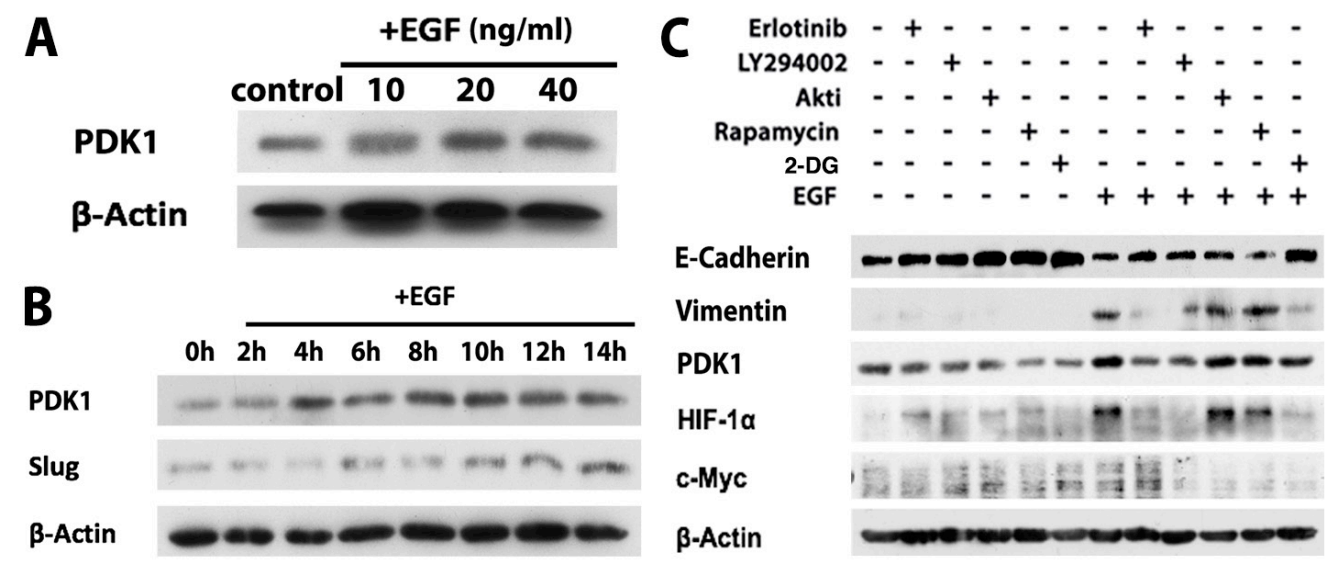

Figure 5: EGFR/PI3K/HIF-1 $\alpha$ signaling pathways facilitate glycolysis through promoting PDK1 expression in OSCC cells. A. The expression of PDK1 in SCC-1 cells following treatment with different concentrations of EGF for 24h were determined by Western blot. B. The expression of PDK1 and Slug in SCC-1 cells following treatment with 20ng/mL EGF for different time periods was determined by Western blot. C. SCC-1 cells were pretreated with specific inhibitors for EGFR (Erlotinib), PI3K (LY294002), Akt (AKTi), mTOR (rapamycin), or 2-DG for $1 \mathrm{~h}$ followed by stimulation with or without EGF for 24h, and the expression of E-cadherin, Vimentin, PDK1, HIF-1 $\alpha$, and c-Myc was determined by Western blot. The expression of $\beta$-actin was used as internal controls. 
A

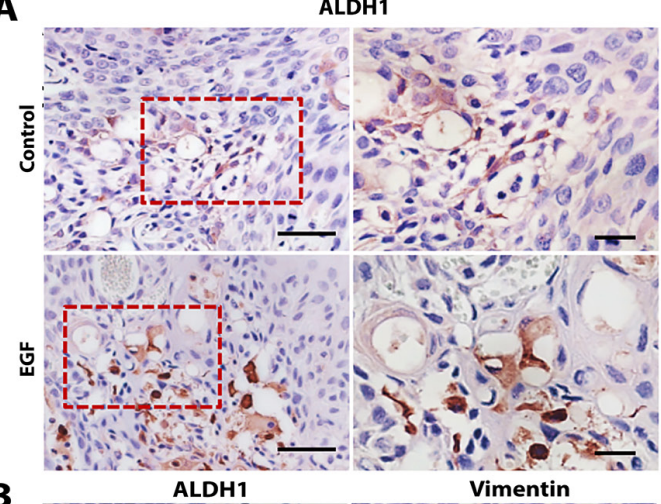

B

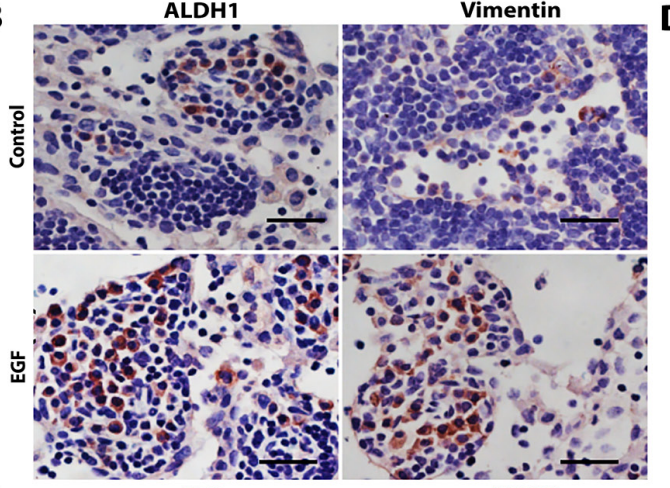

C

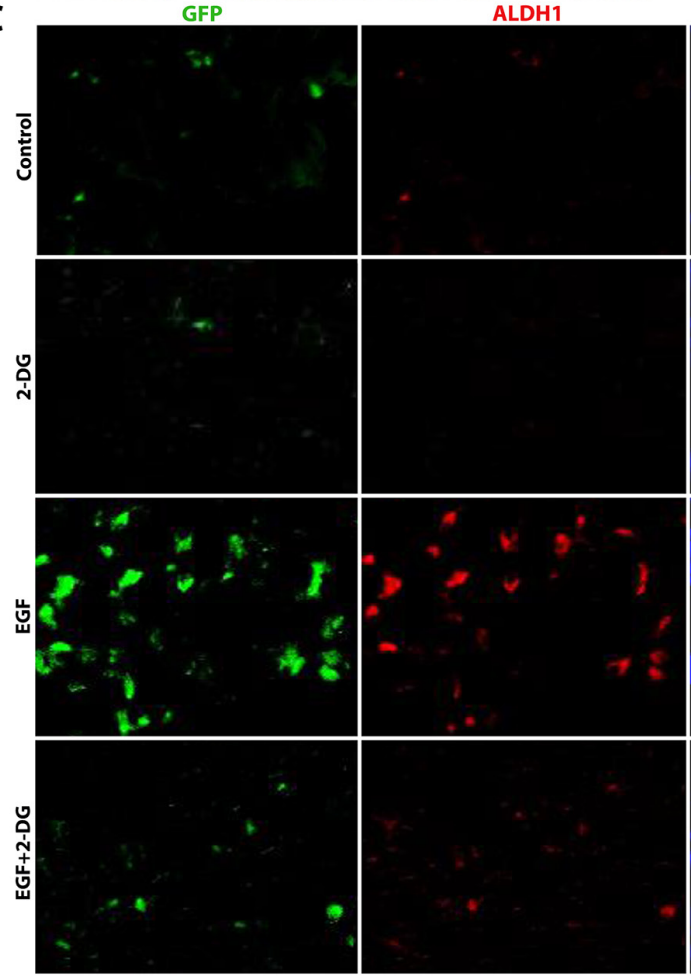

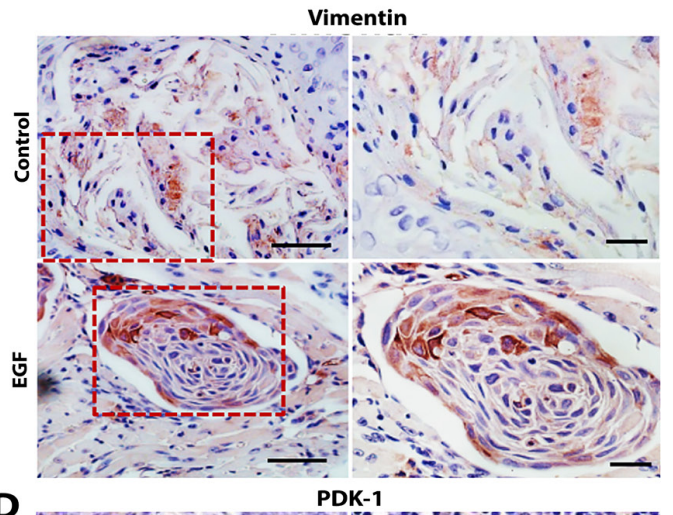
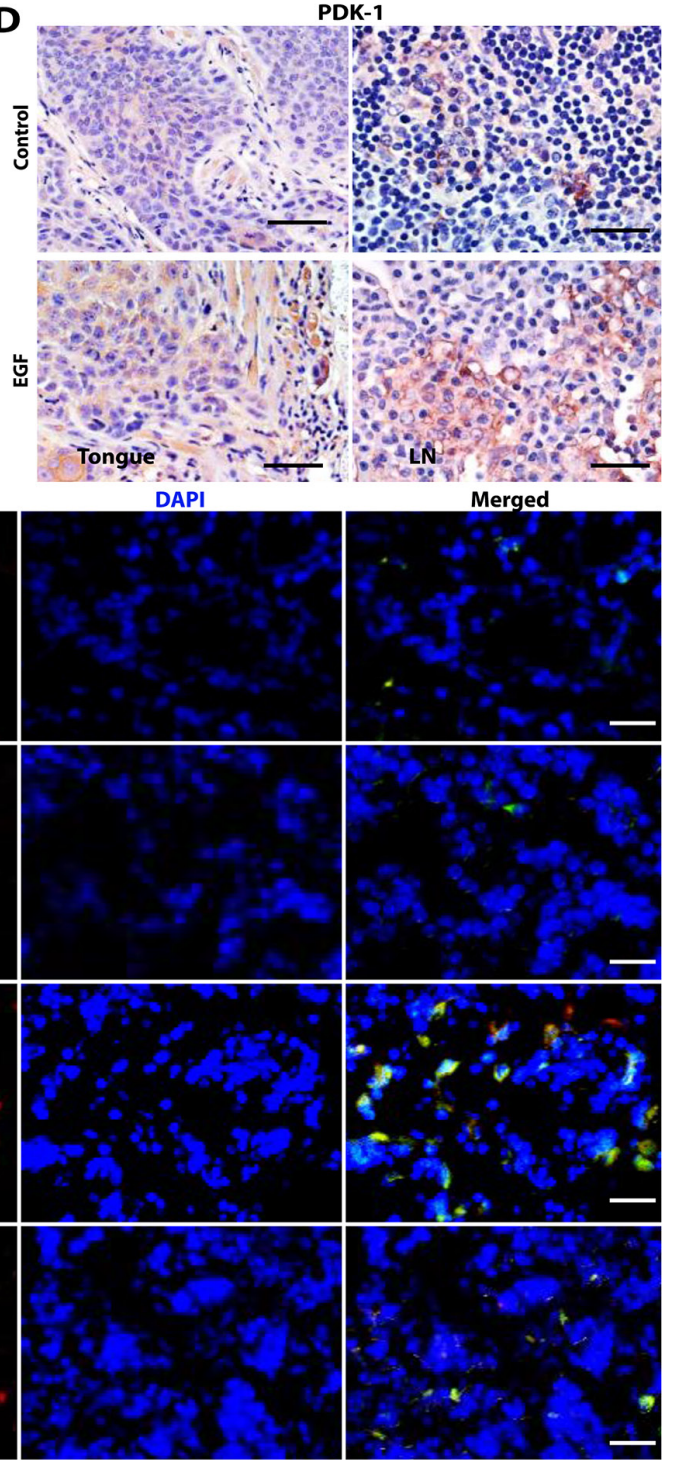

Figure 6: 2-DG treatment suppresses EGF-facilitated regional cervical lymph node metastasis in an orthotopic tongue model of OSCCs in nude mice. A. EGF increased the expression of ALDH1 and vimentin in primary orthotopic SCC-1 tumors in the tongue as determined by immunohistochemical (IHC) studies. The left panels, $10 \times$ magnification, Scale bars, $100 \mu \mathrm{m}$; the right panels, $20 \times$ magnification; Scale bars, $50 \mu \mathrm{m}$. B. The expression of vimentin and ALDH1 in metastatic SCC-1 cells at cervical lymph nodes was

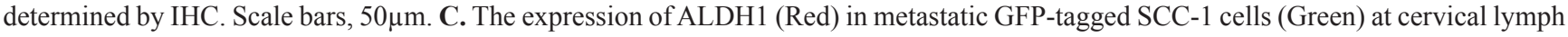
nodes was determined by immunofluorescence staining and observed under a fluorescence microscope; the nuclei were counter stained with DAPI. Scale bars, $50 \mu \mathrm{m}$. D. The expression of PDK1 in primary orthotopic tumors in the tongue (the left panels) and the cervical lymph nodes (LN) (the right panels) was determined by IHC staining. Scale bars, $50 \mu \mathrm{m}$. 
Table 1: Incidence of cervical lymph node (LN) metastasis

\begin{tabular}{lcccc}
\hline & Groups & No. of Mice & $\begin{array}{c}\text { No. of Mice with LN } \\
\text { Metastasis }\end{array}$ & Percentage (\%) \\
\hline I & SCC1 & 10 & 2 & 20.0 \\
II & SCC1+2-DG & 10 & 0 & 0 \\
III & SCC1 + EGF & 10 & 7 & $70.0^{*}$ \\
IV & SCC1+EGF+2-DG & 10 & 3 & $30.0^{*}$ \\
& & & ${ }^{*} P=0.038$ (III v.s. I) & $\# P=0.101$ (IV v.s. III) \\
\hline
\end{tabular}

and bidirectional (EMT vs. MET), thus contributing to the plastic states of cancer cells. The plasticity of cancer cells is controlled by both intrinsic biochemical processes and extrinsic bi-directional cues derived from cancerous and non-cancerous cells in tumor microenvironment [14]. Increasing evidence supports the notion that the plastic property of neoplastic non-stem cells allows them to be reprogrammed into a more primitive, stemlike phenotype $[14,39]$. From this point of view, CSCs may not be a distinct cellular entity but rather represent a state of tumor cells that transiently acquire stem celllike properties as a consequence of EMT process, thus contributing to the uncontrollable metastasis, relapse, and therapeutic resistance. Therefore, a better understanding of the complex network that orchestrates the EMT process may hold a great promise for the development of novel therapeutic approaches to eradicate various types of cancers that are currently resistant to conventional therapies.

EGF, one of the most abundant growth factors found in the tumor microenvironment, can be produced by cancer cells per se and non-cancerous cells such as mesenchymal stromal cells [40], endothelial cells [22], and macrophages $[41,42]$. The abundance of EGF together with the overexpression of EGFR observed in diverse types of cancers, including head and neck cancer [7, 22, 34], lead to aberrant activation of the downstream signaling pathways that facilitate EMT process [40, 41], which subsequently renders cancer cells with plastic properties and increased invasive and metastatic capabilities [22, $34,41]$. Herein, we have demonstrated that activation of EGF/EGFR signaling pathways facilitates the EMT process and enrichment of $\mathrm{ALDH}^{+} / \mathrm{CD} 44^{\text {high }} \mathrm{CSC}$-like cells with increased invasiveness/metastasis potentials both in vitro and in vivo. These findings, together with previous studies by others [22,34], support the notion that the EMT process and acquisition of CSC-like phenotypes driven by the activated EGF/EGFR signaling cascades may play a critical role in the metastasis and recurrence of OSCC.

Even though EGFR activation leads to aberrant EMT process and acquisition of CSC-like properties under various settings [22, 40, 41], the beneath mechanisms remain largely unknown. Most recently, several studies have demonstrated the relation between EGFR activation and dysregulated Warburg effect or aerobic glycolysis in tumor cells [28, 34, 43, 44]. On one hand, EGFR activation promotes tumorigenesis probably by enhancing glycolysis [35, 45], while blocking EGFR activity leads to the reversal of the Warburg effect $[28,44]$. On the other hand, blocking glycolysis sensitizes non-small cell lung cancer cells with a T790M mutation to the treatment with irreversible EGFR inhibitors [43]. Consistently, in the present study we have shown that EGF stimulation significantly enhanced glycolysis in OSCCs possibly by upregulating PDK1 expression and blocking glycolysis almost completely abolished EGF-induced EMT process and acquisition of CSC-like phenotypes in OSCCs both in vitro and in vivo. These compelling findings support the notion that the dysregulated "Warburg effect" may play a critical role in the EMT process and acquisition of CSC-like phenotype driven by aberrant activation of EGF/ EGFR signaling cascades.

Previous studies have shown that over $90 \%$ of HNSCC overexpress EGFRs and the majority of them are resistant to conventional chemo- and radiation-therapies $[4,7]$. Cetuximab is the only EGFR inhibitor approved for the treatment of HNSCC, but the response rate is low [8]. Therefore, it is usually used in combination with chemoand radiotherapy for HNSCC [4]. To date, it remains a challenge to unveil the molecular and cellular mechanisms by which HNSCC cells develop the de novo and acquired resistance to EGFR-targeted therapies [4, 6]. A better understanding of the metabolic plasticity or dysregulated metabolic reprogramming of cancer cells may help us to elucidate how they contribute to resistance to conventional chemo- and radiation therapies and EGFR-targeted therapies. Recent studies have shown that targeting the unique metabolic properties can specifically eliminate cancer stem cells or tumor initiating cells [46, 47]. Currently, we have provided the first line of evidence that blocking glycolysis using 2-DG remarkably suppressed EGF-facilitated regional cervical LN metastases of OSCCs. All together, these findings suggest that targeting cellular metabolism may become a new paradigm to improve the responses of cancer cells to both conventional and EGFR-targeted therapeutics for HNSCC. 


\section{MATERIALS AND METHODS}

\section{Animals}

Six- to eight-week-old female Athymic NCr-nu/ nu mice were purchased from NCI (Frederick, MD) and maintained under standard conditions. All animal procedures were handled according to the guidelines of the Institutional Animal Care and Use Committee (IACUC) of the University of Pennsylvania. We adopted a randomized, prospective and controlled animal model design according to all the recommendations of the ARRIVE (Animal Research: Reporting In Vivo Experiments) guidelines. Mice were group-housed in polycarbonate cages (5 animals per cage) in the animal facilities with controlled temperature $\left(23^{\circ} \mathrm{C} \pm 2^{\circ} \mathrm{C}\right), 40-65 \%$ of humidity and a 12 hour light/dark cycle. Mice were acclimatized for at least 1 week prior to the study, fed with a standard laboratory diet and allowed ad libitum access to drinking water.

\section{Cell lines and treatment}

University of Michigan squamous cell carcinoma (UM-SCC-1), a floor-of-the mouth squamous cell carcinoma derived from tumor recurrence, was kindly provided by Professor Cun-yu Wang (University of California, Los Angeles) and cultured in RPMI-1640 supplemented with $10 \%$ fetal bovine serum (FBS), 100IU/ $\mathrm{ml}$ penicillin, $100 \mu \mathrm{g} / \mathrm{ml}$ streptomycin [48]. UPCI: SCC116 , an alveolar ridge SCC, was kindly provided by Professor Susanne M. Gollin (Head and Neck Spore Grant at University of Pittsburgh Cancer Institute) [49] and cultured in MEM medium supplemented with MEM-nonessential amino acid (NEAA) (Invitrogen), gentamycin, and $10 \%$ FBS. CAL27 (ATCC ${ }^{\circ}$ CRL-2095'TM), a human tongue squamous cell carcinoma cell line, and $\mathrm{FaDu}\left(\mathrm{ATCC}{ }^{\circledR} \mathrm{HTB}-43^{\mathrm{TM}}\right.$ ), a human squamous cell carcinoma cell line derived from the hypopharynx, were both obtained from ATCC [50] and cultured in DMEM supplemented with $10 \%$ fetal bovine serum (FBS), 100IU/ $\mathrm{ml}$ penicillin, $100 \mu \mathrm{g} / \mathrm{ml}$ streptomycin.

Cells were stimulated with different concentrations of EGF $(0 \sim 40 \mathrm{ng} / \mathrm{ml})$ (PeproTech) for $48 \mathrm{~h}$ in the presence or absence of 5mM 2-deoxy-glucose (2-DG) (Sigma), a recognized glycolysis inhibitor. To study downstream EGFR signaling pathway, cells were pretreated with $5 \mu \mathrm{M}$ Erlotinib (Cell Signaling Technology), an EGFR tyrosine

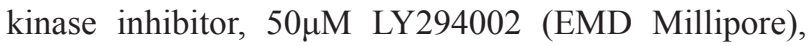
a PI3K inhibitor, or $20 \mu \mathrm{M}$ AKT inhibitor (EMD Millipore), or $2.5 \mu \mathrm{M}$ Rapamycin (EMD Millipore), an mTOR inhibitor, in serum-free RPMI for $1 \mathrm{~h}$ followed by stimulation with EGF for $4 \mathrm{~h}$.

\section{Establishment of stable GFP-expressing cell lines}

A pLL3.7 lentiviral GFP vector was a kind gift from Dr. Andy Peng Xiang (Sun Yat-sen University, China)
[51]. pMD2.G (VSV-G) envelope plasmid (\#12259) and psPAX2 packaging plasmid (\#12260) were from Addgene. Lentiviral products were produced by cotransfection of 293FT packaging cells using Lipofectamine 2000. Briefly, 293FT cells were pre-plated in $10-\mathrm{cm}$ tissue culture plates $\left(6.5 \times 10^{6}\right.$ cells/plate $)$ in DMEM with $10 \%$ FBS so that they were about $90 \sim 95 \%$ confluent on the day of transfection. 293FT cells were cotransfected with $5 \mu \mathrm{g}$ of pMD2.G (VSV-G) envelope plasmid, 10 $\mu \mathrm{g}$ of psPAX2 packaging plasmid and $15 \mu \mathrm{g}$ of lentiviral construct plasmids. $12 \mathrm{~h}$ later, the culture medium was replaced with $10 \mathrm{ml}$ fresh complete culture medium. The lentivirus-containing supernatants from the transfected cells were collected $48-72 \mathrm{~h}$ after transfection, filtered with $0.45 \mu \mathrm{m}$ Millex-HV filters, aliquoted and stored at $-80^{\circ} \mathrm{C}$. SCC- 1 cells were plated in 6 -well plate $\left(1 \times 10^{5}\right.$ cells/well) and transduced overnight with $1 \mathrm{ml}$ lentiviruscontaining supernatant at a multiplicity of infection (MOI) of 10 in the presence of $8 \mu \mathrm{g} / \mathrm{ml}$ polybrene (Sigma) and then remove the culture medium and replace with $2 \mathrm{ml}$ of complete medium without polybrene. $48 \mathrm{~h}$ after transduction, SCC-1 cells were subjected for selection with $2 \mu \mathrm{g} / \mathrm{ml}$ puromycin and continuously subcultured. The transduction efficiency was determined by observation under a fluorescence microscope (Olympus XF-73). Meanwhile, the $\mathrm{GFP}^{+}$cells were further sorted using a cell sorting flow cytometer (FACS Aria D; Flow Cytomerty \& Cell Sorting Facility, University of Pennsylvania School of Medicine).

\section{Flow cytometry and cell sorting}

Cells were harvested and washed twice with PBS containing 2\% heat-inactivated FBS, and resuspended in cell staining buffer (BioLegend, San Diego, CA) at a concentration of $10^{7} / \mathrm{ml}$. Cell suspensions were incubated with PE-CD44 and FITC-CD24 antibodies (BD Biosciences, San Diego, CA), or an isotype-matched mouse $\mathrm{IgG}$ control at $4^{\circ} \mathrm{C}$ for $30 \mathrm{~min}$. Then, the samples were washed twice with $\mathrm{PBS} / 2 \%$ FBS and submitted to flow cytometric analysis (BD LSRII). For cell sorting, cells were collected and immunostained with PE-CD44 and FITC-CD24 antibodies, or stained with Aldefluor kit (Stem Cell Technologies) using diethylaminobenzaldehyde (DEAB, a specific inhibitor of ALDH activity) as negative control followed by immunostained with PE-CD44 antibody. The stained cells were then submitted for cell sorting using a cell sorting flow cytometer (FACS Aria D).

\section{Glucose uptake and lactate secretion}

Cells were seeded in 6-well flat-bottomed plates at a density of $5 \times 10^{5}$ cells per well and treated with EGF or 2-DG at the indicated concentration in culture medium for $48 \mathrm{~h}$. The glucose uptake was determined by Glucose Uptake Cell-based Assay Kit (Cayman Chemical) following manufactures' instructions. All 
cells were analyzed with a flow cytometer. In parallel experiments untreated and treated cells were analyzed for lactate levels in the conditioned media. Briefly, after different treatments, conditioned media were removed, centrifuged at $13000 \times \mathrm{g}$ at $4^{\circ} \mathrm{C}$ for $10 \mathrm{~min}$ and then assayed for lactate concentration using the L-lactate assay kit (Eton Biosciences) following manufactures' instructions. Absolute lactate levels were calculated from the corresponding standard curve and normalized by cell numbers.

\section{Hematoxylin and eosin $(\mathrm{H} \& \mathrm{E})$ staining and immunohistochemistry (IHC)}

Dissected tumor tissues and metastatic lymph nodes from tumor-bearing nude mice were fixed with $4 \%$ PFA and embedded in paraffin. 5- $\mu \mathrm{m}$ thick sections were deparaffinized with xylene and rehydrated in graded ethanol. For the purpose of antigen retrieval, the sections were incubated in sodium citrate buffer $(10 \mathrm{mM}, \mathrm{pH}$ 6.0 ) at $95^{\circ} \mathrm{C}$ for $20 \mathrm{~min}$. After blocking with $2.5 \%$ goat serum in PBS, the sections were incubated overnight at $4^{\circ} \mathrm{C}$ with primary antibodies $(1: 200)$ for vimentin (rabbit IgG; Cell Signaling Technology, Danvers, MA, USA), ALDH1 (rabbit IgG; Cell Signaling Technology), or PDK-1(rabbit IgG; Enzo Life Sciences, Inc., Farmingdale, NY). For the subsequent steps, sections were stained with VECTASTAIN Universal ABC Elite Kit (PK-7200; Vector Labs, Burlingame, CA) and colors were developed using VECTOR NovaRED Substrate Kit (SK-4000; Vector Labs) according to the manufacture's procedures and briefly counterstained with hematoxylin and observed under a light microscope with a digital camera.

\section{Immunofluorescence studies}

For immunofluorescence staining, 10- $\mu$ m-thick frozen sections or cultured cells on 8-well chamber slides were fixed in 4\% PFA for $10 \mathrm{~min}$ at room temperature followed by permeabilization with $0.1 \%$ Triton-X100 and blocking with $2.5 \%$ goat serum in PBS. Then, samples were incubated at $4^{\circ} \mathrm{C}$ overnight with primary antibodies for E-cadherin (mouse IgG, Santa Cruz Biotechnology, Santa Cruz, CA), CD44 (mouse IgG; BD Biosciences, San Diego, CA), vimentin (rabbit IgG; Cell Signaling Technology), Bmi-1(rabbit IgG; Santa Cruz Biotechnology), or ALDH1(rabbit IgG; Cell Signaling Technology), followed by incubation with FITC- or rhodamine-conjugated secondary antibodies (1:400; BioLegend, San Diego, CA) at room temperature for $1 \mathrm{~h}$. An isotype control IgG was used as nonspecific controls. The nuclei were counterstained with 4', 6-diamidino2-phenylindole (DAPI) contained in the mounting medium (Vector Labs) and images were observed under a fluorescence microscope (Olympus XF-73).

\section{D-cell invasion assay}

The invasion ability of parental SCC-1 in the presence or absence of $20 \mathrm{ng} / \mathrm{mL} \mathrm{EGF}$, the sorted $\mathrm{CD}_{4} 4^{+} /$ CD24- and $\mathrm{CD}^{-} 4^{-} / \mathrm{CD} 24^{+}$cells was determined using the $\mathrm{QCM}^{\mathrm{TM}}$ Collagen-based Cell Invasion Assay Kit according to the manufacturer's protocol (Millipore). Cells were seeded into upper inserts at $1 \times 10^{5}$ per insert in serum-free DMEM. Outer wells were filled with DMEM containing $10 \% \mathrm{FBS}$ or $20 \mathrm{ng} / \mathrm{mL}$ EGF as chemoattractants. Cells were incubated at $37^{\circ} \mathrm{C}$ with $5 \% \mathrm{CO}_{2}$ for $48 \mathrm{~h}$. The noninvading cells were removed by swabbing top layer of collagen with Q-tips, while cells migrated through the gel insert to the lower surface of the membrane were stained and photographed under a microscope at $40 \times$ objectives [20]. To determine the effect of EGF on cell proliferation, SCC-1 cells were seeded into 96-wells $\left(1 \times 10^{4} /\right.$ well in triplicate $)$ and cultured in the presence or absence of $20 \mathrm{ng} / \mathrm{mL}$ EGF for $48 \mathrm{~h}$ and the proliferation was determined using [3-(4,5-dimethylthiazol-2-yl)-2,5diphenyltetrazolium bromide] (MTT) assay.

\section{siRNA transient transfection}

SCC- 1 cells $\left(2 \times 10^{5} /\right.$ well $)$ were seeded into 6-well plates and transfected with a pool of 3 target-specific 1925nt siRNA for SLUG1 (sc-38393; Santa Cruz Biotech) or ZEB1 (sc-156138; Santa Cruz Biotech); a non-specific siRNA (sc-36869, Santa Cruz) was used as control. Following transfection for $5 \mathrm{~h}$, the transfection medium was replaced with fresh complete medium and cells were cultured for overnight followed by stimulation with EGF (20ng/ml) for $48 \mathrm{~h}$.

\section{Western blot analysis}

Cell lysates $(50 \mu \mathrm{g}$ of total protein) were separated on polyacrylamide-SDS gel and electroblotted onto nitrocellulose membrane (BioRad, Hercules, CA). After blocking with $\mathrm{TBS} / 5 \%$ nonfat dry milk, the membrane was incubated with antibodies against E-cadherin (mouse IgG, Santa Cruz Biotechnology), vimentin (mouse IgG, Santa Cruz Biotechnology), ZEB1, ZO-1, Slug, ALDH1, p-Akt (Ser473), EGFR, or p-EGFRs (rabbit IgG; Cell Signaling Technology) followed by incubation with a horseradish peroxidase (HRP)-conjugated secondary antibody, and the signals were visualized by enhanced chemiluminescence detection (ECL) (PIERCE, Rockford, IL). The blots were also re-probed with a specific antibody against $\beta$-actin (Santa Cruz Biotechnology).

\section{An orthotopic OSCC model in the tongue of nude mouse}

Subconfluent GFP-tagged SCC-1 cells were harvested, washed and resuspended in PBS. $1 \times 10^{5}$ cells suspended in $30 \mu \mathrm{L}$ of PBS were injected into the lateral 
tongue as described previously [50, 52]. To observe the effect of EGF on tumor growth and lymph node metastasis, $30 \mu \mathrm{L}$ of Hydrogel containing $1 \times 10^{5}$ GFPtagged SCC-1 cells with/without EGF (20ng/ml) was injected submucosally into anterior-sublingual portion of tongue. Two days after tongue injection of tumor cells, mice were intraperitoneally (i.p.) administered with 2-DG $(500 \mathrm{mg} / \mathrm{kg})$ every other day. Mice with orthotopic tumor transplantation treated with the vehicle were used as control $(n=10)$. Body weight was assessed twice a week. After 4 weeks, the mice were sacrificed with $\mathrm{CO}_{2}$, and the tongue tumors and cervical lymph nodes were removed, fixed in 4\% PFA and processed for further analysis. Tumor volume was calculated as $V=A B^{2}(\pi / 6)$, where $A$ is the longest dimension of the tumor and $B$ is the dimension of the tumor perpendicular to $A$. The presence of cervical lymph node and distant lung metastasis was evaluated by the presence of GFP signals and the Hematoxylin and eosin (H\&E) staining [53-55].

\section{Statistical analysis}

All data are presented as mean \pm standard deviation (SD). The Student's paired or independent $t$-tests were used to analyze the differences in vitro experimental data $[54,55]$, while incidence rate of lymph node metastasis was analyzed using Fisher's exact test [56]. A values of $P<0.05$ was considered to be statistically significant. Statistical analyses were performed using SPSS 18.1statistical software program (SPSS Inc., Chicago, IL, USA).

\section{ACKNOWLEDGMENTS}

This work was supported by National Institute of Health Research Grant, R01DE 019932, Oral and Maxillofacial Surgery Foundation (OMSF) Research Grant, and the Schoenleber funding support.

\section{CONFLICTS OF INTEREST}

The authors declare no conflicts of interest.

\section{GRANT SUPPORT}

This work was supported by National Institute of Health Research Grant, R01DE 019932, Oral and Maxillofacial Surgery Foundation (OMSF) Research Grant, and the Schoenleber funding support.

\section{Author contributions}

Conception and design: A. Le, Q. L. Xu, Q. Z. Zhang, C. V. Dang.

Acquisition of data: Q. L. Xu, Y. Ishida, Q. Z. Zhang, S. Hajjar, X. D. Tang, H. R. Shi.
Analysis and interpretation of data: Q. L. Xu.

Writing, review, and/or revision of the manuscript:

Q. L. Xu, Q. Z. Zhang, A. Le, C. V. Dang.

Study Supervision: A. Le.

\section{REFERENCES}

1. Jemal A, Siegel R, Xu J and Ward E. Cancer statistics, 2010. CA Cancer J Clin. 2010; 60:277-300.

2. Sano D and Myers JN. Metastasis of squamous cell carcinoma of the oral tongue. Cancer Metastasis Rev. 2007; 26:645-662.

3. Kuperman DI, Auethavekiat V, Adkins DR, Nussenbaum B, Collins S, Boonchalermvichian C, Trinkaus K, Chen L and Morgensztern D. Squamous cell cancer of the head and neck with distant metastasis at presentation. Head Neck. 2011; 33:714-718.

4. Rabinowits G and Haddad RI. Overcoming resistance to EGFR inhibitor in head and neck cancer: a review of the literature. Oral Oncol. 2012; 48:1085-1089.

5. Siegel R, Naishadham D and Jemal A. Cancer statistics, 2012. CA Cancer J Clin. 2012; 62:10-29.

6. Chong CR and Janne PA. The quest to overcome resistance to EGFR-targeted therapies in cancer. Nat Med. 2013; 19:1389-1400.

7. Ford AC and Grandis JR. Targeting epidermal growth factor receptor in head and neck cancer. Head Neck. 2003; 25:67-73.

8. Misiukiewicz K, Dang RP, Parides M, Camille N, Uczkowski H, Sarlis NJ and Posner M. Endothelial growth factor receptor inhibitors in recurrent metastatic cancer of the head and neck. Head Neck. 2016; 38:E2221-2228.

9. Dorsey K and Agulnik M. Promising new molecular targeted therapies in head and neck cancer. Drugs. 2013; 73:315-325.

10. Wheeler DL, Dunn EF and Harari PM. Understanding resistance to EGFR inhibitors-impact on future treatment strategies. Nat Rev Clin Oncol. 2010; 7:493-507.

11. Vermorken JB, Trigo J, Hitt R, Koralewski P, Diaz-Rubio E, Rolland F, Knecht R, Amellal N, Schueler A and Baselga J. Open-label, uncontrolled, multicenter phase II study to evaluate the efficacy and toxicity of cetuximab as a single agent in patients with recurrent and/or metastatic squamous cell carcinoma of the head and neck who failed to respond to platinum-based therapy. J Clin Oncol. 2007; 25:2171-2177.

12. Soulieres D, Senzer NN, Vokes EE, Hidalgo M, Agarwala SS and Siu LL. Multicenter phase II study of erlotinib, an oral epidermal growth factor receptor tyrosine kinase inhibitor, in patients with recurrent or metastatic squamous cell cancer of the head and neck. J Clin Oncol. 2004; 22:77-85.

13. Ksiazkiewicz M, Markiewicz A and Zaczek AJ. Epithelialmesenchymal transition: a hallmark in metastasis formation linking circulating tumor cells and cancer stem cells. Pathobiology. 2012; 79:195-208. 
14. Kreso A and Dick JE. Evolution of the cancer stem cell model. Cell stem cell. 2014; 14:275-291.

15. Prince ME, Sivanandan R, Kaczorowski A, Wolf GT, Kaplan MJ, Dalerba P, Weissman IL, Clarke MF and Ailles LE. Identification of a subpopulation of cells with cancer stem cell properties in head and neck squamous cell carcinoma. Proceedings of the National Academy of Sciences of the United States of America. 2007; 104:973-978.

16. Mannelli G and Gallo O. Cancer stem cells hypothesis and stem cells in head and neck cancers. Cancer Treat Rev. 2012; 38:515-539.

17. Sinha N, Mukhopadhyay S, Das DN, Panda PK and Bhutia SK. Relevance of cancer initiating/stem cells in carcinogenesis and therapy resistance in oral cancer. Oral Oncol. 2013; 49:854-862.

18. Chen JS, Pardo FS, Wang-Rodriguez J, Chu TS, Lopez JP, Aguilera J, Altuna X, Weisman RA and Ongkeko WM. EGFR regulates the side population in head and neck squamous cell carcinoma. The Laryngoscope. 2006; 116:401-406.

19. Bhaijee F, Pepper DJ, Pitman KT and Bell D. Cancer stem cells in head and neck squamous cell carcinoma: a review of current knowledge and future applications. Head \& neck. 2012; 34:894-899.

20. Zhang Q, Shi S, Yen Y, Brown J, Ta JQ and Le AD. A subpopulation of $\mathrm{CD} 133(+)$ cancer stem-like cells characterized in human oral squamous cell carcinoma confer resistance to chemotherapy. Cancer letters. 2010; 289:151-160.

21. Mani SA, Guo W, Liao MJ, Eaton EN, Ayyanan A, Zhou AY, Brooks M, Reinhard F, Zhang CC, Shipitsin M, Campbell LL, Polyak K, Brisken C, Yang J and Weinberg RA. The epithelial-mesenchymal transition generates cells with properties of stem cells. Cell. 2008; 133:704-715.

22. Zhang Z, Dong Z, Lauxen IS, Filho MS and Nor JE. Endothelial cell-secreted EGF induces epithelial to mesenchymal transition and endows head and neck cancer cells with stem-like phenotype. Cancer Res. 2014; 74:2869-2881.

23. Koppenol WH, Bounds PL and Dang CV. Otto Warburg's contributions to current concepts of cancer metabolism. Nat Rev Cancer. 2011; 11:325-337.

24. Bayley JP and Devilee P. The Warburg effect in 2012. Curr Opin Oncol. 2012; 24:62-67.

25. Dong C, Yuan T, Wu Y, Wang Y, Fan TW, Miriyala S, Lin Y, Yao J, Shi J, Kang T, Lorkiewicz P, St Clair D, Hung MC, Evers BM and Zhou BP. Loss of FBP1 by Snail-mediated repression provides metabolic advantages in basal-like breast cancer. Cancer Cell. 2013; 23:316-331.

26. Tasselli L and Chua KF. Cancer: Metabolism in 'the driver's seat. Nature. 2012; 492:362-363.

27. Vander Heiden MG, Cantley LC and Thompson CB. Understanding the Warburg effect: the metabolic requirements of cell proliferation. Science. 2009; 324:1029-1033.
28. Velpula KK, Bhasin A, Asuthkar S and Tsung AJ. Combined targeting of PDK1 and EGFR triggers regression of glioblastoma by reversing the Warburg effect. Cancer Res. 2013; 73:7277-7289.

29. Butler EB, Zhao Y, Munoz-Pinedo C, Lu J and Tan M. Stalling the engine of resistance: targeting cancer metabolism to overcome therapeutic resistance. Cancer Res. 2013; 73:2709-2717.

30. Davis FM, Azimi I, Faville RA, Peters AA, Jalink K, Putney JW, Jr., Goodhill GJ, Thompson EW, Roberts-Thomson SJ and Monteith GR. Induction of epithelial-mesenchymal transition (EMT) in breast cancer cells is calcium signal dependent. Oncogene. 2014; 33:2307-2316.

31. Cordonnier T, Bishop JL, Shiota M, Nip KM, Thaper D, Vahid S, Heroux D, Gleave $M$ and Zoubeidi A. Hsp27 regulates EGF/beta-catenin mediated epithelial to mesenchymal transition in prostate cancer. Int J Cancer. 2014.

32. Cho KH, Choi MJ, Jeong KJ, Kim JJ, Hwang MH, Shin SC, Park CG and Lee HY. A ROS/STAT3/HIF-1alpha signaling cascade mediates EGF-induced TWIST1 expression and prostate cancer cell invasion. Prostate. 2014; 74:528-536.

33. Muthusami S, Prabakaran DS, Yu JR and Park WY. EGF-induced expression of Fused Toes Homolog (FTS) facilitates epithelial-mesenchymal transition and promotes cell migration in ME180 cervical cancer cells. Cancer Lett. 2014; 351:252-259.

34. Wang Y, Lin Z, Sun L, Fan S, Huang Z, Zhang D, Yang Z, Li J and Chen W. Akt/Ezrin Tyr353/NF-kB pathway regulates EGF-induced EMT and metastasis in tongue squamous cell carcinoma. British journal of cancer. 2013; 110:695-705.

35. Yang W, Zheng Y, Xia Y, Ji H, Chen X, Guo F, Lyssiotis CA, Aldape K, Cantley LC and Lu Z. ERK1/2-dependent phosphorylation and nuclear translocation of PKM2 promotes the Warburg effect. Nat Cell Biol. 2012; 14:1295-1304.

36. Kim JW, Tchernyshyov I, Semenza GL and Dang CV. HIF1-mediated expression of pyruvate dehydrogenase kinase: a metabolic switch required for cellular adaptation to hypoxia. Cell metabolism. 2006; 3:177-185.

37. Kim JW, Gao P, Liu YC, Semenza GL and Dang CV. Hypoxiainducible factor 1 and dysregulated c-Myc cooperatively induce vascular endothelial growth factor and metabolic switches hexokinase 2 and pyruvate dehydrogenase kinase 1 . Molecular and cellular biology. 2007; 27:7381-7393.

38. Dang CV, Kim JW, Gao P and Yustein J. The interplay between MYC and HIF in cancer. Nature reviews Cancer. 2008; 8:51-56.

39. Chaffer CL, Brueckmann I, Scheel C, Kaestli AJ, Wiggins PA, Rodrigues LO, Brooks M, Reinhardt F, Su Y, Polyak K, Arendt LM, Kuperwasser C, Bierie B and Weinberg RA. Normal and neoplastic nonstem cells can spontaneously convert to a stemlike state. Proceedings of the National Academy of Sciences of the United States of America. 2011; 108:7950-7955. 
40. Castano Z, Marsh T, Tadipatri R, Kuznetsov HS, Al-Shahrour F, Paktinat M, Greene-Colozzi A, Nilsson B, Richardson AL and McAllister SS. Stromal EGF and igf-I together modulate plasticity of disseminated triple-negative breast tumors. Cancer Discov. 2013; 3:922-935.

41. Yang J, Liao D, Chen C, Liu Y, Chuang TH, Xiang R, Markowitz D, Reisfeld RA and Luo Y. Tumor-associated macrophages regulate murine breast cancer stem cells through a novel paracrine EGFR/Stat3/Sox-2 signaling pathway. Stem Cells. 2013; 31:248-258.

42. Cardoso AP, Pinto ML, Pinto AT, Oliveira MI, Pinto MT, Goncalves R, Relvas JB, Figueiredo C, Seruca R, Mantovani A, Mareel M, Barbosa MA and Oliveira MJ. Macrophages stimulate gastric and colorectal cancer invasion through EGFR Y(1086), c-Src, Erk1/2 and Akt phosphorylation and smallGTPase activity. Oncogene. 2014; 33:2123-2133.

43. Kim SM, Yun MR, Hong YK, Solca F, Kim JH, Kim HJ and Cho BC. Glycolysis inhibition sensitizes non-small cell lung cancer with T790M mutation to irreversible EGFR inhibitors via translational suppression of Mcl-1 by AMPK activation. Mol Cancer Ther. 2013; 12:2145-2156.

44. Lu H, Li X, Luo Z, Liu J and Fan Z. Cetuximab reverses the Warburg effect by inhibiting HIF-1-regulated LDH-A. Mol Cancer Ther. 2013; 12:2187-2199.

45. Baulida J, Onetti R and Bassols A. Effects of epidermal growth factor on glycolysis in A431 cells. Biochem Biophys Res Commun. 1992; 183:1216-1223.

46. Ciavardelli D, Rossi C, Barcaroli D, Volpe S, Consalvo A, Zucchelli M, De Cola A, Scavo E, Carollo R, D'Agostino D, Forli F, D'Aguanno S, Todaro M, et al. Breast cancer stem cells rely on fermentative glycolysis and are sensitive to 2-deoxyglucose treatment. Cell Death Dis. 2014; 5:e1336.

47. Feng W, Gentles A, Nair RV, Huang M, Lin Y, Lee CY, Cai $\mathrm{S}$, Scheeren FA, Kuo AH and Diehn M. Targeting unique metabolic properties of breast tumor initiating cells. Stem Cells. 2014; 32:1734-1745.

48. Kim J, Guan J, Chang I, Chen X, Han D and Wang C-Y. PS-341 and histone deacetylase inhibitor synergistically induce apoptosis in head and neck squamous cell carcinoma cells. Molecular cancer therapeutics. 2010; 9:1977-1984.
49. Bock JM, Sinclair LL, Bedford NS, Jackson RE, Lee JH and Trask DK. Modulation of cellular invasion by VEGF-C expression in squamous cell carcinoma of the head and neck. Arch Otolaryngol Head Neck Surg. 2008; 134:355-362.

50. Sano D, Xie TX, Ow TJ, Zhao M, Pickering CR, Zhou G, Sandulache VC, Wheeler DA, Gibbs RA, Caulin C and Myers JN. Disruptive TP53 mutation is associated with aggressive disease characteristics in an orthotopic murine model of oral tongue cancer. Clin Cancer Res. 2011; 17:6658-6670.

51. Ke Q, Li L, Cai B, Liu C, Yang Y, Gao Y, Huang W, Yuan $\mathrm{X}$, Wang $\mathrm{T}$ and Zhang Q. Connexin 43 is involved in the generation of human-induced pluripotent stem cells. Human molecular genetics. 2013; 22:2221-2233.

52. Myers JN, Holsinger FC, Jasser SA, Bekele BN and Fidler IJ. An orthotopic nude mouse model of oral tongue squamous cell carcinoma. Clin Cancer Res. 2002; 8:293-298.

53. Uchida D, Begum N-M, Tomizuka Y, Bando T, Almofti A, Yoshida $\mathrm{H}$ and Sato M. Acquisition of lymph node, but not distant metastatic potentials, by the overexpression of CXCR4 in human oral squamous cell carcinoma. Laboratory investigation. 2004; 84:1538-1546.

54. Endo K, Ueno T, Kondo S, Wakisaka N, Murono S, Ito M, Kataoka K, Kato Y and Yoshizaki T. Tumor-targeted chemotherapy with the nanopolymer-based drug NC-6004 for oral squamous cell carcinoma. Cancer Sci. 2013; 104:369-374.

55. Gan CP, Patel V, Mikelis CM, Zain RB, Molinolo AA, Abraham MT, Teo SH, Abdul Rahman ZA, Gutkind JS and Cheong SC. Heterotrimeric G-protein alpha-12 (Galpha12) subunit promotes oral cancer metastasis. Oncotarget. 2014; 5:9626-9640. doi: 10.18632/oncotarget.2437.

56. Garmy-Susini B, Avraamides CJ, Desgrosellier JS, Schmid MC, Foubert P, Ellies LG, Lowy AM, Blair SL, Vandenberg SR, Datnow B, Wang HY, Cheresh DA and Varner J. PI3Kalpha activates integrin alpha4beta1 to establish a metastatic niche in lymph nodes. Proceedings of the National Academy of Sciences of the United States of America. 2013; 110:9042-9047. 